\title{
Study on Progress of Developing Strategy on Ports Cluster: Integration of Port Resources
}

\author{
Zhanxin Xiao ${ }^{1,2}$, Liuyu Zhou ${ }^{2}$, Jin Liang ${ }^{2}$, Hongzhong Li $^{2,3}$ \& Zihan Hong ${ }^{4}$ \\ ${ }^{1}$ School of Geography and Planning, SunYat-sen University, Guangzhou, 510275, China \\ ${ }^{2}$ Research Center for earth environment \& resources of Sun Yat-sen University, Guangzhou, 510275, China \\ ${ }^{3}$ Institute of Geology and Geophysics, Chinese Academy of Science, Beijing, 100029, China \\ ${ }^{4}$ University of International Relations, Peking University, Beijing, 100871, China
}

Correspondence: Zhanxin Xiao, School of Geography and Planning, SunYat-sen University; Research Center for earth environment \& resources of Sun Yat-sen University, Guangzhou, 510275, China. E-mail: eeszhxxin@sina.com; Hongzhong Li, Research Center for earth environment \& resources of Sun Yat-sen University, Guangzhou, 510275, China; Institute of Geology and Geophysics, Chinese Academy of Science, Beijing, 100029, China. E-mail: lihongzhong01@aliyun.com

Received: April 1, 2014 Accepted: April 28, 2014 Online Published: May 16, 2014

doi:10.5539/jgg.v6n2p145 URL: http://dx.doi.org/10.5539/jgg.v6n2p145

\begin{abstract}
Ports play important roles in linking transportation routes and distributing cargo, which promote the national and regional economy and trade development. Although ports formerly dominated the distribution and transportation of cargo in the era of sailing boats all over the world, their monopoly has been challenged more and more fiercely during the process of economic globalization and integration. Under the current economic conditions, the competition or opposition between the ports are not suitable for their normal operation. In order to adapt to the ongoing reformation of sea transportation, it is inevitable that port resources integrate to take advantage of complementary cooperation. As the integration of resource can optimize the allocation of the limited port resources, it brings about overall advantage to promote the development of port cluster and regional economy. However, a lot of problems would still need to face in the practical process. To meet the requirements of economic and social development, the researchers have launched a large number of theoretical and practical researches in their field about the development of port resource integration. So, the theoretical and practical researches in the published papers are studied to open out the significances of port resource integration and seek after the solution to the problems in development of ports in the present study.
\end{abstract}

Keywords: port resource, integration, water carriage, solution, theory

\section{Introduction}

Ports are the hub and node of networks for the river-transportation, lake-transportation, sea-transportation and reservoir-transportation (Chen, 2003). They play important roles in linking transportation routes and distributing cargo (Wang, 2006), and therefore promote the national and regional economic and trade development (Huang \& Chen, 1990; Luo, 1991; Zou, 1997). Ports are regarded as an important carrier and ideal role in international logistics (Zhuang \& Wang, 2005). In the process of development of world trade, ports formerly dominated the world's cargo distribution and transportation in the era of sailing boats (Xie, 2007). However, the growth of shipping company and shipper has presented fierce challenge against their monopoly in the process of economic globalization and integration (de Langen \& Visser, 2005; de Langen, 2004a, 2006). Under current economic conditions, complete competition or opposition between ports is not suitable for their normal operation (de Langen \& Visser, 2005; Cheng \& Wei, 2009; Liu, 2008a; Lu, 2008; Liu, 2008b). In order to adapt to the ongoing reform of sea transportation, it is inevitable that the port resources should be integrated to take advantage of complementary cooperation ( $\mathrm{Li}, 2007$; $\mathrm{Su}, 2007$; Wu et al., 2007). In this situation, scholars have paid a lot of attention to the ports in areas including Guangdong ( $\mathrm{Lv} \& \mathrm{Lu}, 2009)$ (ports in Guangzhou City (Guo, 2007)), Liaoning (Zhao \& Sun, 2007; Wang, 2007; Geng et al., 2009; Tan \& Chen, 2007; Zhao et al., 2007) (Jingzhou Port (Mao, 2008; Wang \& Ren, 2009)), Shandong (Wang, 2009a; Liu, 2009), Zhejiang (Xu, 2008a) (Huanyueqing Bay (Chen, 2007) and Ningbo-zhoushan Port (Xu, 2008a)), Guangxi (Shi \& Lu, 2007) (Beibu 
Gulf (Xie, 2007; Xiong, 2008)), and the port cluster in area including Liaodong Peninsula (Wang, 2009c), Shandong Peninsula, Yangzi River Delta (Dong, 2006; Zhang \& Liu, 2008a; Wang, 2009b), Pearl River Delta (Lv, 2007) and West-shore of Bohai Gulf. Some scholars have put forward the development pattern of "Main Port Pattern" (Wang, 2008). Thus, the previous studies on integrations of port resources are discussed here to explore the problems, solutions and significances of the integration of port resources.

\section{Port and Port Cluster}

\subsection{Port}

Ports are the hub and node of river-, lake-, sea- and reservoir-transportation networks (Xu, 2007; Liu, 2006). A port includes the waters and the adjacent land, possessing certain equipment and conditions to run campaigns like shipping, cargo transportation and so on. There are many classifications of ports. They can be geographically classified as sea port, estuary port, river port, lake port and reservoir port, or be classified as business port, fishing port, military port and refuge port based on their purpose.

With the development of international economy, international trade and transportation, the range of campaign of ports have been enlarged and go through four different eras (Alderton, 2008). According to the definition of the first, second and third generation port by the UNCTAD, the second and third version of Port Management and Operations have made comprehensive discussion about the age, condition and function of the four generation of ports (Alderton, 2005, 2008):

(1) First Generation Ports were joint points that only connect sea transportation and inland transportation before 1960s. They were separated away from commercial trade activities and served as a place only for cargo shifting. As an independent entity, port had little connection with local government or clients, which demonstrated as a function of shifting cargo between ships and shores. Otherwise, all the businesses of port were isolated from each other in some degree, and the cargos were mainly break bulk cargo.

(2) Second generation ports existed in between 1960s to 1980s and severed as places for load and unload as well as providing some industrial and commercial service. Furthermore, they erected some partnership connecting transportation and trade, permitting cargo owners (especially large cargo) to set up facilities to deal with cargos within the port. Close relationships with local relevant parties were established and advanced management ideas and approaches were adopted to keep broad-eyesight in port running and developing strategy. Moreover, the businesses of port were integrated and industrial and server facilities were added within port. The majority of cargos were break bulk cargo and bulk cargo.

(3) Third generation ports possess more initiative in management and become hubs and nodes of international production and transportation nets generally between 1980s and 1990s. Their businesses were more specialized, integrated and flexible. Much more importance was attached to value added service of primary commodities. Moreover, more consideration about planning and building information processing facilities was added in the plan of infrastructure construction of the ports. Ports tended to integrate environmental protection, client convenience, customs formalities and institutional framework. The majority of the cargos were bulk cargo and united cargo.

(4) Forth generation ports are modern ports that get improved since 1990s to promote economic development and server international trade. Modern ports devote themselves to the standardization of port information and operation sequence, automation of facilities and equipment, informatization and globalization of operating management, which favor transnational operation of large-scale shipping enterprises. As for cargo, the majority of them tend to be unitization.

It is obvious that the major distinctions among the four generation are labor and capital, capital, technology, specialty and information technology (Alderton, 2008).

\subsection{Port Cluster System}

Ports are the hub and node of river-, lake-, sea- and reservoir-transportation networks. They play important roles in linking transportation routes and distributing cargo, which promotes national economic and regional economic and trade development. Port system which is constituted by ports that some or part of their functions can be substituted for each other is called Port Cluster (Fang, 2000). This concept is first put up at the Surrounded-Sea Highway of Mediterranean Countries Conference in July 2012, and defined as several ports that could be effectively connected through highway and railway within certain geographical extent (such as 50 100 miles) (Gou, 2009). Based on the purpose of the research and the area get involved, port clusters could be classified in many ways (Xu, 2007; Yuan, 2005; Wei, 2007), such as different port districts in the same port (Jinzhou Port and Hulugang Port in western Liaoning (Mao, 2008)), different ports in the same province (Guangzhou Port, 
Shenzheng Port, Shantou Port, Zhuhai Port, Zhanjiang Port in Guangdong Province), different ports in the same area (port clusters in Bohai Sea District, Yangzi River Delta, Pearl River delta, Southeastern Coast and Southeastern Coast), or even coastal ports within a country (like port cluster constituted by ports along China coast) could be regarded as a large port cluster. From the theory of port cluster establishment and performance evaluation system (de Langen, 2004a), conclusion draw from the comparison between Rotterdam Port Cluster and Mississippi Down Branch Port Cluster is that, five collective acts which are vital to the development of port cluster are education and training, creativity, market exploitation and advertisement, hinterland connection and internationalization (de Langen \& Visser, 2005).

With port cluster as its basis, the Port Cluster System is formed when two or more ports share common economic hinterland (Sun \& Xu, 2004) (port economic hinterland is region where cargo transportation is directly or indirectly finished by the port due to the limitation of transportation route or convenience (Wang, 2006)). Port Cluster System is also called Regional Port (Zhang \& Liu, 2008b), covering ports geographically close and communicational connected, such as Yangzi River Delta Port Cluster including Shanghai Port, Ningbo Port and Taicang Port, Pearl River Delta Port Cluster including Hong Kong Port, Shenzhen Port and Guangzhou Port (Fang, 2000).

Thus, Port Cluster is the product of ports when their functions and scales have developed to a certain point. Its appearance is inevitable during the process of economic development and trade expansion.

\section{Integration of Port Resource}

\subsection{Port Resource}

Resource is the foundation of human subsistence and development. In the field of economy, resource includes not only natural resources like mineral, climate, water conservancy, land and biological resource (Liu \& Cai, 2000), but also human resource (labor force, management and technology), capital resource (non-monetary physical assets and monetary assets) and informational resource (resources as carrier to connect natural resource, human resource and capital resource) (Xu, 2007; Yuan, 2005; Li, 2008). As for any given period, the resource of a society is always limited, but the demand of human is limitless. Thus, it is necessary to optimize the allocation of the limited resource to meet the limitless human demand ( $\mathrm{Lu} \& \mathrm{Chen}, 2008$ ).

There are narrow and general conceptions of port resource ( $\mathrm{Li}, 2008$; $\mathrm{Xu}, 2006)$. In narrow sense, port resource is physical resource of ports, like dock water front, waters, lands, and port facilities. In general sense, port resource is resource that make port as an important joint point in the modern logistics serve chain, core in the synthesize logistics, carrier of the transportation net; it includes capability resource, client resource, public social resource and informational resource that connect all of those resources. The specific contents are as follows ( $\mathrm{Li}$, 2008).

(1) Capability resource, including dock water front, waters, lands, infrastructure construction, capital, port brand, human resource, technology and route resource.

(2) Clint resource, including upstream and downstream firms that relevant to logistics and supply chain of the port, such as shipping enterprises, cargo owner enterprises, shipping agencies, cargo agencies and logistics enterprises.

(3) Public social resource, including freight resource, collection and distribution channel, hinterland economy situation, policy and institution, environment of the port (city finance, insurance, bonded area, customs clearance environment) and so on.

(4) Informational resource, including EDI system, port producing management system, port office automation management system, port assist decision-making system, port logistics trade information platform, inter-port information sharing mechanism, port service knowledge, IT system and so on.

\subsection{Integration of Port Resource}

As an important concept in economy, the distribution of resource is defined as "What a society can produce using given resource, how, and for whom (Samuelson \& Nordhaus, 2004)". However, the rational distribution of resources is a concept in field of economic efficiency, including two levels $(\mathrm{Li}, 2008$; Samuelson \& Nordhaus, 2004; Shao, 2006). The first one is the "efficiency of resource utility", which refers to how a production unit, area or department make the best use of limited resources and avoid waste. It means producing the most valuable product with given production factors. The second level is the "efficiency of resource distribution", which refers to how different production unit, area and department distribute limited resource among each other. That is distributing every kind resource to the most suitable unites. The former demonstrates as "production efficiency", 
which is achieved through improving internal controls and advancing productive technology; the later demonstrates as "economic institution efficiency", which is achieved through the flowing of external production factors. That is obtained by institutional arrangements. Pareto optimal standard is the universal standard measuring the distribution of social resources. It bases on the theory of marginal benefit and means increasing the efficiency of anybody (at least one) without the decreasing of others' efficiency. That is adding more marginal benefit than the marginal cost in the process of distributing resources. Pareto inefficiency is rising the efficiency of one or some people through resources redistribution under the situation that the efficiencies of others remain the same. This kind of resource redistribution is also called Pareto improvement. When the redistribution of resource meet the Pareto optimal standard, optimization status is achieved, which is important standard and evidence to assess the optimization of port resources.

In a sense, the integration of port resource is kind of mean to realize the optimization of resource distribution (Yuan, 2005; Luo, 2008). That is making use of the coast line and positional advantage depending on port cluster advantage, promoting economic profits of port resource system investment through proper integration of port resources. The full play of port functions can support sustainable development and build up modern port cluster that is well arranged, reasonably constructed, perfectly functioned and efficiently coordinated. That is the aim of resource integration is enhancing economic efficiency, social efficiency and core competitiveness.

\section{Basis and Mode of Port Resource Integration}

\subsection{Theory Basis and Thinking in Integration}

According to system theory (Wei, 1995), local optimization doesn't guarantee system optimization. As for resource integration, resource could be saw as a whole system and be processed and reformed to a more inter-connected and reasonable-constructed structure, so each part could coordinately develop to maximize the effect of the whole system and its general profit. Thus, resource integration can be interpreted as "adjust, coordinate optimize and reorganized the given resources to gain integral optimum". The key of the concept demonstrate in the following two aspects (Xu, 2007; Yuan, 2005): first is to maximize the development and increase of the given resource within possible range, second is to make scientific allocation and use of given resource to gain soundest profit.

As for port, resource integration is actually the process to redistribute and optimize port resource macroscopically and microcosmically ( $\mathrm{Li}, 2008 ; \mathrm{Xu}, 2006$ ). The macroscopic part is by the way of organizing and coordinating to integrate the relative but separate parts inside the port and the economically independent but have common mission parts outside the port to be a logistic system which could serve transportation as well, and try to gain effect of " $1+1>2$ ". The microcosmic part is through optimizing the policies of port resource distribution to redistribute the resource of the port to fit the development of the port and to meet the requirement of the market, which can find out the best combination point between resource distribution and market requirement while outlining the core-competitiveness of the port (Xu, 2006; Shao, 2006). The accordance between port distribution and industries distribution decides that the unreasonable industries distribution is the key factor that led to the unreasonable distribution of the port. Thus, the priority to integrate port resource is to solve the problem of industries distribution (Luo, 2008). So, from the aspect of system theory, economy and resource utility, the general thinking to integrate port resource can be demonstrated as follow.

(1) Identify the role of each port according to the industry development of its hinterland.

(2) United plan the distribution of ports and utility of coastline according to industry distribution and port role identify.

(3) Adjust the port and industry distribution functionally and structurally according to relative plan.

(4) Realize the functional complementation, labor cooperation and coordinately development by reasonable planning.

\subsection{Integration Models}

Resource integration of port is to make all ports open to each other (resource sharing, advantage complementation and function divide and cooperate) (de Langen \& Chouly, 2004). Previous researchers have already proposed different models base on different situation (Cheng \& Wei, 2009; Wu et al., 2007; Liu, 2009; Zhang \& Liu, 2008a, 2008b; Li, 2008; Luo, 2008) which will be extended in the following context.

(1) There are diversities in the connection degree between different ports, which contribute to distinct league with their proper trait.

(i) One is closely-connect alliance model (Li, 2008), which means all ports are so closely connect that they can 
be regarded as one. Those ports will make up development strategy corporately and share profit and risk. This is the supreme model of port integration; it combines different interest groups and achieves maximized interaction and utilizes of resource like production factors, technology, information and human resources, and turn primary competition into internal competition. This model is popular abroad, like New York / New Jersey Port, Los Angel/Long Beach Port in the USA, and the alliance of Antwerp Port, Zeebrugge Port in Belgium.

(ii) The other is loosely-connect alliance model (Li, 2008; Luo, 2008), which includes two types. The first one is formed by relatively independent ports which just ally with each other for certain objective. The second one is formed by completely independent ports which are just mutual beneficent with each other. As for these two types, the six ports alliance of Tokyo Bay in Japan belongs to the first one. They form the alliance which is unstable since their loosely-connect mutual interest (the alliance may develop toward a more positive direction on the basic of good cooperation, or just broke down due to some uncertain factors), just to gain the advantage position in the field of container transportation. The alliance of Hong Kong port and Shenzhen Port belongs to the second type. They are completely independent to each other but complement to each other closely. The Hong Kong port chooses to ally with Shenzhen port due to factors like its lack in land, high port construction and labor cost, and environment deterioration. Shenzhen gains capital, technical and manager profit from the alliance as well. Thus, their cooperation can develop greatly.

In general, loosely-connected alliance tends to become closely-connected one if they are run well.

(2) According to the management after allying.

(i) One is Government leading model, which is managed by the government of both sides. The advantage of this model is that government can provide favorable external environment for the development of ports by exerting macroscopic control with its power in policy making (Coeck, 2002). This form of resource integration is more common abroad, such as New York-New Jersey Ports (Chen \& Shao, 2007) and Los Angle-Long Beach Ports in USA, Tokyo Bay Ports in Japan (Chen \& Shao, 2007). The enterprises run the operation and production of the ports, and the governments take charge in policy and strategy making, infrastructure construction, security in production, environmental protection and so on.

(ii) The other is enterprise dominant model, which is formed by independent enterprises without any government involvement. This kind of cooperation is rational choice that in accordance with the role of market economy. It advantage is rapid reaction and flexibility in change. In the primary period when the Heji Huangpu Group participated in developing Shenzhen Yantian Harbor District, they invest large number of money to fill in the deficit of the shipping company every year. In return, the container transportation of Yantian Harbor District developed rapidly and the company gained sound profit finally.

(3) Based on the level of port integration.

(i) Entirely integration, which means all the coastline, cargo terminal of near ports are integrated into one port brand to form a single port. This kind of integration is the most thorough one that it can efficiently integrate the planning, constructing, branding and managing together. This kind of ports usually possess the common harbor distribute, port entrance channel and economic hinterland, all of those elements have their own developing advantages. The integration of resource will avoid repeat constructions and can give full play to their own characters and realize dislocation development.

(ii) Single integration, which means neighbor ports have cooperation on certain cargos. This kind of cooperation is usually taken place between large-scale ports and small scale ports. In order to improve competiveness, small-scale ports need to resort to large-scale port since they don't own the ability to open up international line independently. In return, large-scale ports gain additional source of cargo. Under this integration, all ports are independent from each other without any hierarchy.

(4) Regional integration, which usually occur to two adjacent ports which own rich deep-water coastline resource in between them and the condition to be developed into large-scale port. If the two ports develop independently or just one of them get developed, it will cause waster in the coastline resource between them and violate the role of full utilize of available resource. Under this integration, the disintegrate part of the port will be developed independently to compete and cooperate with the integrate port of the ports. Under certain condition, this kind of integration is similar to the previously put-forward "asset link integration" (Luo, 2008).

(5) There are diversities in business of the port resource in different ports, which can possibly contribute to the multi-pass transportation. In consideration on this possibility, the multi-pass transportation of the port (Luo, 2008) is conducted as follows.

(i) The first type is trans-river linkage integration, which aims to integrate ports lack in coastline resource and 
ones rich in them through trans-river linkage integration. Based on infrastructure construction, this model will promote the linkage development of industries near the port distribute through carriers as industry linkage development zone. Under the promotion of government at various levels, ports can achieve trans-river integration with this model to realize coordinate development between ports.

(ii) The second type is transportation system integration, whose integration for the whole transport system is proposed according to the planning of the overall layout of the port. From the characteristics of multi-pass transportation of the major cargo in different ports, the department of manager could integrate the whole transport system through general planning.

\section{Common Problems and Solutions in Integration}

Based on the requirement of economic development, researchers have paid significant attention to the definition of ports and port cluster (Fang, 2000), their evolution and development (Alderton, 2008; Sun \& Xu, 2004), competition (Dong, 2006; Lv \& Zhang, 2006; Teurelincx, 2000) and cooperation (Wang, 2004) between port clusters, and integration of port resources (Yuan, 2005), especially the integration of resource of ports in different regions in our country (Cheng \& Wei, 2009; Geng et al., 2009; Gou, 2009; Li, 2007, 2008; Li \& Liu, 2009; Liu, 2008a, 2009; Luo, 2008; Shi \& Lu, 2007; Zhao et al., 2007; Wang, 2007, 2008, 2009a, 2009b, 2009c; Wang \& Ren, 2009; Wei, 2007; Wu et al., 2007; Xiong, 2008; Xu, 2006; Yuan, 2005; Zhang \& Liu, 2008a; Zhang \& Liu, 2008b; Zhao \& Sun, 2007). On this basement, some researchers have put forward a system of comprehensive evaluation index (de Langen, 2004a; Wei, 2007) and dynamic model of coordinate development (Fang, 2000). From these researches, we can find that beside objective factors like location, natural condition, hinterland and the degree of economic development which do matter in the value of ports, resource integration is also important in improving the value of the ports.

In the process of economic globalization, only advance development of ports can concentrate resource to certain region $(\mathrm{Xu}, 2007)$. Ports are not only infrastructure construction that serves local economy but also hub and node in global resource distribution, which can be proved by the development of global ports. Along with the rapid increase of international trade, ports in all countries put forward plans to expanse and enlarge the capability of loading, unloading and transiting. Thus, it is undoubtedly important for ports to integrate resources. Although resource integration can optimize resource distribution while forming general advantage for the port cluster and economic development, many problems will be faced during the process of resource integration (Wang \& Ren, 2009; Xu, 2007; Gou, 2009; Yuan, 2005; Visser \& Boschma, 2004). According to the work of previous researcher (Chen, 2007; Cheng \& Wei, 2009; Zhao et al., 2007; Wang \& Ren, 2009; Xu, 2008a, 2008b; Dong, 2006; Xu, 2007; Gou, 2009; Yuan, 2005; Chen \& Shao, 2007; Sun \& Xu, 2004; Li, 2008; Luo, 2008; Lv \& Zhang, 2006; Wang, 2004), the following suggestions are proposed to guaranty the integration.

First, improve relative rules and regulations for the running of ports. Legislation is indispensable since ports can't run normally and orderly without the legal management. The January $1^{\text {st }} 2004$ Port Law of the People's Republic of China have provided important guarantee in aspect like port security and management, protection of legitimate rights and interests of concerned parties, and promotion in legal management and development. However, a lot of rules and regulation need to be drawn concerning specific problems. Thus, the normal running of ports is dependent on the situation of lawmaking.

Second, detach government and enterprise and reform traditional management system. Due to the influence of planned economy, government-enterprise mix-ups do exist in domestic port management. If ports administering authorities work from their own interests and ignore the general effectiveness of the whole cluster, it will cause waste in port resource and affect the development of the port industry (de Langen, 2004b). Thus, the reforming traditional port management institution and detaching government and enterprise is crucial issue to be faced in the process of port resource integration and fitting into the market competition.

Third, division of labor and positioning of ports included in the port cluster. In the process of development, from the view of their interest, different ports certainly strive for more resources within the cluster to improve their status. Thus, when it comes to the integration of port resource, labor and position division is necessary to make sure the reasonable development and utilize of resources and promote the economic development of the region. In this way, maximize of profit of enterprises can be achieved.

Fourth, chose proper way to improve the effect of resource integration. Port resource integration is a complex system project. All enterprises, local governments and related interest groups will get involved. Thus, proper way and reasonable plan are the precondition for the process and final result of the integration.

Fifth, explore the proper way of cooperation to guarantee the interest of all parties. All enterprises and local 
governments within in the region will get involved in the integration, thus it is a complex project. In this way, it is important to find out the proper way to make sure the integration can move on smoothly.

Sixth, establish sound cooperate and compete institution. Competition is the hallmark of market, which can push the optimization of port resources. Competition is always demonstrated in two aspects. First, healthy competition leads to the improvement of the quality of port serves. Second, exceed and disorder competition lead to the waste of port resources. Thus, establishing reasonable and ordered cooperate and compete institution is the key and difficulty for the integration of port resources. It can determine whether the integrated port can run well afterward.

Seventh, cultivate core-competitiveness. Core-competitiveness is the most powerful weapon to reinforce the competitiveness of enterprise. The clients choose ports base on many factors, including loading and unloading machine, sparse conditions, cost, security, efficiency, custom, the availability of berth machinery, or even the existence of bonded zone (Murphy, 1992). Usually, cost and efficiency are the most important factors of the consideration of clients (Barton \& Turnbull, 2002), thus cost, operating environment, and sparse condition could affect the choice of clients.

Eighth, encourage innovation to occupy the commanding elevation. The orientation of development of ports of world in $21 \mathrm{C}$ is deep-water constructing, network distributing, logistics operating, informational managing, and private managing. The new elements that affect the efficiency of port competitiveness include the increase demand for time and space of chained-transport market and the more perfect of various environmental rules to regulate the running of ports $(\mathrm{Xu}, 2007)$. Thus, it is very important to make suitable economic policy to encourage innovation to increase the core-competitiveness of ports (Goss, 1990).

\section{Conclusion}

As the hub and node of transportation networks, ports formerly dominated the world's cargo distribution and transportation in the era of sailing boats. They play so important roles in promoting national and regional economic and trade development that they are regarded as an important carrier and ideal role in international logistics. However, the growth of shipping company and shipper has presented fierce challenge against their monopoly in the process of economic globalization and integration. In order to make better use of the given resource to fit in the rapid development of the society and economy, ports and port clusters encounter many problems in field of resource integration. This has been proved by the system theory, economic theory, resource theory and facts. All the problems point to a key that resource integration plays the same important role in port development as factors like location, natural condition, hinterland and the degree of economic development. Although resource integration can optimize resource distribution while forming general advantage for the port cluster and economic development, many problems need to face during the process of resource integration. If one can detach government and enterprise and reform traditional management system, divide labor and positioning of ports reasonably to protest the interest of different parties, the process of integration can go on smoothly. With the perfection of rules and regulation to promote cooperative and competitive mechanism, and improvement of management to encourage innovation, ports will finally develop great core-competitiveness.

\section{References}

Alderton, P. M. (2005). Port management and operations (2nd ed.). London: Lloyds of London Press.

Alderton, P. M. (2008). Port management and operations (3rd ed., pp. 1-250). London: Informa Maritime \& Transport, Informa UK Limited.

Barton, H., \& Turnbull, P. J. (2002). Labour regulation and competitive performance in the port transport industry: The changing fortunes of three major European seaports. European Journal of Industrial Relations, 8, 133-156.

Chen, L. Q. (2003). Development of modern ports and port logistics industry. Comprehensive Transportation, 1, 30-31.

Chen, M., \& Shao, J. G. (2007). Enlightenment of foreign port cluster of competition and cooperation to our country. China Ports, 4, 47-49.

Chen L. G. (2007). Integration of port resource in ring area of Yueqing Bay. China Water Transport, 5(1), 38-39.

Cheng, A. J., \& Wei, L. H. (2009). Bohai Gulf's win-win cooperation: Enlightenments from port cluster resources integration model of developed area. Management and Administration, 3, 36-38.

Coeck, C. (2002). Essays on Strategy Analysis for Seaports. International Journal of Maritime Economics, 4(2), 
185-187. http://dx.doi.org/10.1057/palgrave.ijme.9100037

de Langen, P. W. (2004a). The performance of seaport clusters, a frame work to analyze cluster performance and an application to the seaport clusters of urban, Rotterdam, and the Lower Mississippi. Rotterdam: Erasmus.

de Langen, P. W. (2004b). Governance in seaport clusters. Maritime Economics \& Logistics, 6(2), 141-156.

de Langen, P. W. (2006). Chapter 20 Stakeholders, Conflicting Interests and Governance in Port Clusters. Research in Transportation Economics, 17, 457-477. http://dx.doi.org/10.1016/S0739-8859(06)17020-1

de Langen, P. W., \& Chouly, A. (2004). Hinterland access regimes in seaports. European Journal of Transport and Infrastructure Research, 4, 361-380.

de Langen, P. W., \& Visser, E. (2005). Collective action regimes in seaport clusters: the case of the Lower MississiPPi Port cluster. Journal of Transport Geography, 13(2), 173-186. http://dx.doi.org/ 10.1016/j.jtrangeo.2004.04.010

Dong, G. (2006). Application of the Game Theory on port competition and cooperation strategies. China Water Transport, 7, 200.

Fang, R. (2000). Port cluster system dynamics model of coordinated development. Shipping Management, 2, 6-11.

Geng, D. H., Feng, S. S., \& Hou, X. K. (2009). Port resources integration during development in coastal economic belt of Liaoning Province. China Ports, 8, 15-16.

Gou, Z. G. (2009). Study on resource integration and developing scale in Liaoning province littoral port cluster. Dalian: Dalian Maritime University.

Goss, R O. (1990). Economic policies and seaports: The diversity of port policies 1. Maritime Policy \& Management, 17(3), 221-234.

Guo, L. F. (2007). Carry forward the spirit of Zheng He and speed up the development of inland port in the west bank of pearl river mouth. Pearl River Water Transport, 7, 29-30.

Huang, D. M., \& Chen, F. X. (1990). Port Economy (pp. 1-290). Chongqing: Chongqing Publishing House.

Li, N., \& Liu, C. X. (2009). An research on port cluster resources integration and coordinated development of the west bank of the Bohai Gulf. Economic Outlook the Bohai Sea, 8, 1-4.

Li, Q. (2008). Study on Appraisal of the Resources Allocation and Integration Countermeasure in Shandong Coastal Port Cluster. Dalian: Dalian Maritime University.

Li, X. (2007). Heibei Province integration the three major port resourcess. Port Economy, 2, 25.

Liu, B. P., \& Cai, Y. L. (2000). Introduction to Earth Science (pp. 1-368). Beijing: Higher Education Press.

Liu, L. (2009). Construction of port cluster of Hebei Province: Enlightenments from port resources integration model of Shandong Province. Journal of Xingtai University, 24(1), 15-18.

Liu, X. L. (2006). Xiamen Port Logistics Development Analysis. Fuzhou: Fujian Normal University.

Liu, X. Y. (2008a). Do well in the port resources integration and promote development of the industry. Science \& Technology of Ports, 1, 5-8.

Liu, X. Y. (2008b). Resources integration promotes the ports to surging like spring tide. China Water Transport, $3,9-10$.

Lu, C. (n.d.). The trend of port resources integration is irreversible. China Ports, 6, 6-9.

Lu, X. X., \& Chen, Y. E. (2008). Microeconomics (2nd ed., pp. 1-348). Beijing: Economic Science Press.

Luo, X. L. (2008). Study on Integration of Port resources about Grain Logistics in Dalian Port. Dalian: Dalian Maritime University.

Luo, Z. Q. (1991). Port Economy (pp. 1-293). Beijing: Academy Press.

Lv, R. S., \& Zhang, Z. Y. (2006). Development of circum-Bohai-sea region ports: Enlightenments from port business strategy of Japan. Contemporary Economy of Japan, 5, 61-64.

Lv, X. (2007). Development trend and strategies of port cluster container wharf of the Pearl River estuary. China Ports, 9, 31-37.

Lv, X., \& Lu, M. S. (2009). Integrate resourcess to promote the ability of port to serve economy and society. 
Shipping Management, 31(11), 29-31.

Mao, B. K. (2008). Take the port integration of Western Liaoning as a breakthrough, and make port resources integration of Liaoning Province come true. Port Economy, 9, 13-15.

Murphy P., Daley J., \& Dalenberg D. (1992). Port selection criteria:An application of a transportation research framework. Logistics and Transportation Review, 28, 237-255.

Samuelson, P. A., \& Nordhaus, W. D. (2004). Economics (17th ed., pp. 1-649). Beijing: Posts and Telecom Press.

Shao, Z. Y. (2006). Research on Appraisal and Policy of Optimizing Regional Higher Education Resources Allocation in China. Harbin: Harbin Engineering University.

Shi, H. N., \& Lu, Z. (2007). An research on coastal port resources integration and development tendency of Guangxi. Enterprise Science and Technology \& Development, 18, 138-139.

$\mathrm{Su}, \mathrm{Z}$. (2007). Port resources integration of Xiamen works. Port Economy, 5, 56.

Sun, X. L., \& Xu, C. X. (2004). Competition, cooperation and evolution of the port cluster system. Port \& Waterway Engineering, 10, 28-31.

Tan, Y., \& Chen, S. X. (2007). Speed up provincial port resources integration, optimize and boost the construction of Northeast Asia shipping center in Dalian City. Liaoning Economy, 11, $20-21$.

Teurelincx, D. (2000). Functional Analysis of Port Performance as a Strategic Tool for Strengthening a Port's Competitive and Economic Potential. International Journal of Maritime Economics, 2(2), 119-140.

Visser, E., \& Boschma, R. (2004). Learning in districts: novelty and lock-in in a regional contex. European Planning Studies, 12(6), 793-808.

Wang, G. (2007). The trend and strategy of port resources integration of Liaoning Province. Shipping Management, 29(3), 12-14.

Wang, G., \& Ren, Y. P. (2009). An research on problems and strategies of port logistics resources integration in Jinzhou Gulf. China Storage \& Transport, 2, 110-111.

Wang, H. Y. (2009a). Speed up development of bonded port and promote port resources integration optimally optimize. Theory Front, 10, 45-46.

Wang, L. H. (2009b). Integrate port resources of the Yangtze River Delta, and accelerate construction of Shanghai international shipping center. Journal of Nantong University (Social Sciences Edition), 25(4), 21-25.

Wang, R. X. (2008). Resources integration strategy in our country's port integration: Take Ningbo-Zhoushan Port for example. Economic Geography, 28(5), 872-875.

Wang, W. (2006). Hinterland of port economy and its analysis method. Port Economy, 1, 24-26.

Wang, Y. S. (2009c). Port cluster resources integration of the Liaodong Peninsula. Shipping Management, 31(6), 20-23.

Wang, Z. Z. (2004). The port cluster development of the Yangtze River Delta: In the view point of regional economic development. Comprehensive Transportation, 6, 31-33.

Wei, H. S. (1995). System theory: philosophy of system sciences (pp. 1-359). Beijing: Tsinghua University Press.

Wei, L. (2007). Synthetic Evaluation of China's Coastal port Cluster. Dalian: Dalian Maritime University.

Wu, L. H., Zou, J. W., Chen, S., Chen, Q. L., \& Huang, Q. Y. (2007). Exploration of port resources integration model of Xiamen. China Water Transport, 7(1), 214-216.

Xie, T. W. (2007). Resources integration and regional cooperation of Beibu Gulf (Guangxi) port. Coastal Enterprises and Science \& Technology, 11, 1-4.

Xiong, X. (2008). An research on port resources integration of Beibu Gulf. China Maritime Safety, 1, 57-59.

$\mathrm{Xu}$, B. (2008). Speed up port resources integration and promote the construction of ports. Transportation Construction \& Management, 4, 56-58.

$\mathrm{Xu}$, J. (2007). Port cluster resources integration and its promotion on hinterland economy of the Yangtze River Delta. Shanghai: Shanghai Maritime University.

Xu, Q. (2006). Study on port resources integration of Zhejiang Province. Navigation of China, 3, 68-71, 76. 
$\mathrm{Xu}, \mathrm{Q}$. (2008). Integrate soft resourcess and promote port competitiveness of Zhejiang Province. Journal of Marine Sciences, 26(1), 85-89.

Yuan, B. (2005). Study on the Integration of Port Cluster's resources. Dalian: Dalian Maritime University.

Zhang, X., \& Liu, W. (2008a). Port resources integration model of the Yangtze River Delta. Shipping Management, 30(2), 1-4.

Zhang, X., \& Liu, W. (2008b). Similarities, differences and perspectives of port resources integration model between abroad and the Yangtze River Delta. China Ports, 3, 6-8.

Zhao, N., \& Sun, G. Q. (2007). Port resources integration of Liaoning Province. Shipping Management, 29(2), 21-24.

Zhao, N., Zhao, C. J., \& Sun, G. Q. (2007). Strategy of port resources integration in Liaoning Province. China Water Transport, 1, 16-17.

Zhuang, Q. W., \& Wang, J. (2005). Development of foreign port logistics and its enlightenment. Logistics Technology, 6, 91-94.

Zou, J. S. (1997). Modern Port Economy (pp. 1-334). Beijing: China communication press.

\section{Copyrights}

Copyright for this article is retained by the author(s), with first publication rights granted to the journal.

This is an open-access article distributed under the terms and conditions of the Creative Commons Attribution license (http://creativecommons.org/licenses/by/3.0/). 